\title{
IPTEKS PENERAPAN DAN MANFAAT TEKNOLOGI INFORMASI TERHADAP PROSES BISNIS PERBANKAN PADA PT. BANK RAKYAT INDONESIA (PERSERO) TBK. KANTOR CABANG MANADO
}

\author{
Valencia Matthew Anis ${ }^{1}$, Steven J. Tangkuman ${ }^{2}$ \\ 1,2Jurusan Akuntansi, Fakultas Ekonomi dan Bisnis Universitas Sam Ratulangi, Jl. Kampus Unsrat, Manado, \\ 95115, Indonesia \\ Email: valenciamatthew.anis@yahoo.com
}

\begin{abstract}
The use of information technology plays an important role in the company's business processes. One of the success factors of company performance is the optimal use or application of information technology. Especially in banking business process activities, the use of information technology is one of the weapons in competition in the banking business world. In this article Bank BRI, which is one of the largest banking companies in Indonesia, also relies on information technology in the continuity of its business processes. In this article, we will discuss about the application of the Bank BRI Manado branch office's Information Technology and its benefits in the continuity of banking business processes. In this case the BRI bank Manado branch office uses a variety of information systems in the banking business processes that will be explained in this article.
\end{abstract}

Keywords : Business Processes, Information Technology, Banking business, Information System, Bank

\section{PENDAHULUAN}

Di era yang serba modern ini perkembangan teknologi yang terjadi tidak bisa ditahan perkembangannya. Salah satu perkembangan yang paling menonjol adalah perkembangan teknologi informasi. Di zaman sekarang, setiap orang diberikan kemudahan dalam mengakses setiap informasi yang diinginkan. Itu semua disebabkan oleh perkembangan informasi yang cukup pesat. Begitu juga halnya dengan dunia bisnis perbankan. Dengan adanya teknologi informasi, proses bisnis perbankan dapat berjalan dengan baik dan tersistematis. Kinerja bank dalam melakukan proses perbankan juga dapat dipengaruhi oleh penggunaan teknologi informasi yang baik dan optimal. Semakin maju dan canggih teknologi informasi yang dimiliki oleh suatu bank, semakin berkembang pula kegiatan bisnis perbankan bank tersebut.

PT. Bank Rakyat Indonesia merupakan salah satu badan usaha milik negara (BUMN) yang berkiprah di dunia perbankan. PT. Bank Rakyat Indonesia juga merupakan salah satu perusahaan perbankan terpopuler di Indonesia, yang mempunyai banyak sekali cabang yang beredar di seantero Indonesia. Salah satu cabang PT. Bank Rakyat Indonesia yaitu bank BRI kantor cabang Manado yang terletak di kota Manado, Provinsi Sulawesi Utara. Dalam upaya mengsingkronkan kegiatan bisnis perbankan antara kantor cabang Manado dengan cabang lainnya terlebih khusus dengan cabang pusat, maka diperlukan sistem informasi. Sistem informasi yang digunakan bertujuan untuk menyelaraskan proses bisnis dari cabang satu ke cabang lainnya dan berakhir pada laporan pertanggung jawaban ke kantor pusat. Tentunya terdapat berbagai macam sistem informasi yang digunakan bank BRI kantor cabang Manado yang bermanfaat pada kelancaran proses bisnis perbankan.

\section{TINJAUAN PUSTAKA}

Bank. Menurut UU No.10 tahun 1998, "Bank adalah badan usaha yang mengumpul dana dari masyarakat yang berwujud simpanan dan juga mendistribusikannya kepada 
masyarakat dalam wujud kredit (pinjaman) atau dalam wujud lainnya dalam rangka peningkatan taraf hidup masyarakat".

Menurut Standar Akuntansi Keuangan (PSAK) Nomor 31, "Bank merupakan suatu lembaga yang memiliki peran sebagai pihak perantara keuangan antara entitas-entitas yang memiliki kelebihan dana dan entitas-entitas yang memerlukan dana, serta sebagai lembaga yang berfungsi memperlancar proses pembayaran".

Menurut Hasibuan (2005:2), "Bank merupakan suatu badan usaha yang kekayaannya bersumber dari asset keuangan serta memiliki motif profit dan social, bukan semata-mata hanya sebagai pencari keuntungan".

Teknologi Informasi. Menurut Haag dan Keen (1996), "Teknologi informasi merupakan seperangkat tools (alat) yang dapat membantu suatu pekerjaan dengan informasi dan melakukan tugas-tugas yang berkaitan dengan pemrosesan suatu informasi".

Menurut Information Technology Association of America (ITTA), "Teknologi informasi yaitu suatu pembelajaran, pembuatan, pengaplikasian, peningkatan, patronasi atau manajemen sistem informasi berdasarkan teknologi, lebih khusus pada aplikasi perangkat keras (hardware) dan perangkat lunak (software) computer.

Sistem Informasi. Menurut Erwan Arbie (2000:35), "Sistem informasi merupakan sistem di dalam suatu perusahaan yang mempertemukan kebutuhan pemrosesan transaksi harian, menolong dan mendukung kegiatan operasi, memiliki sifat manajerial dari suatu perusahaan dan membantu mempermudah ketersediaan laporan yang diperlukan".

Menurut O'Brien (2005:5), "Sistem informasi merupakan suatu kombinasi yang tersusun secara sistematis apapun dari people (orang), hardware, piranti lunak (software), jaringan komputer dan jaringan komunikasi serta database yang mengumpulkan, mengubah, dan menyebarkan informasi di dalam suatu bentuk organisasi". Suatu sistem informasi umumnya berasal dari proses kegiatan operasinal yang tetap, yaitu : (1) Mengakumulasikan data; (2) Mengklasifikasikan data; (3) Mengestimasi; (4) Mengkaji; (5) Menyediakan laporan. Manfaat dari sasaran sistem informasi adalah: (1) meningkatkan terselesaikannya suatu proses; (2) meningkatkan efektifitas secara keseluruhan; dan (3) meningkatkan efektifitas ekonomi.

\section{METODE DAN TEKNIK PENERAPAN IPTEKS}

\subsection{Metode Penerapan Ipteks}

Dalam rangka melakukan proses bisnis perbankan dalam konteks pengkordinasian antara kantor cabang bank BRI ke kantor pusat guna menunjang kegiatan perbankan yaitu dengan menerapakan teknologi informasi dalam hal ini dengan menggunakan sistem informasi yang sudah tersedia merupakan metode ipteks yang di terapkan dalam artikel ini. Agar supaya, kegiatan proses bisnis perbankan dapat berjalan dengan optimal.

\subsection{Teknik Penerapan Ipteks}

Teknik ipteks yang di gunakan, yaitu dalam penerapan teknologi informasi bank BRI kantor cabang Manado menggunakan sistem informasi yang terdiri dari 6 aplikasi, yaitu:

1. Core Banking System (CBS)

2. Electronic Banking (E-BANKING)

3. Enterprise Data Model (EDM)

4. Avaibility Jaringan Komunikasi

5. Business Continuity Plan dan Disaster Recovery Plan

6. Security System

\section{PEMBAHASAN}

\subsection{Gambaran Objek Penerapan Ipteks}

PT. Bank Rakyat Indonesia (Persero) Tbk adalah salah satu perusahaan perbankan milik negara terbesar yang ada di Indonesia. Bank BRI berdiri pada tahun 1895. Dari tahun 
1895 sampai dengan tahun 2018, tentunya bank BRI sudah banyak sekali melayani para nasabahnya sehingga dapat bertahan dalam dunia bisnis perbankan. Salah satu cabang bank BRI yang ada di Indonesia terdapat di kota Manado, Sulawesi Utara, yaitu BRI kantor cabang Manado. BRI kantor cabang Manado terletak di jalan Sarapung nomor 4-6, kota Manado, Sulawesi utara. Sama seperti bank lainnya, BRI kantor cabang Manado menyediakan macammacam pelayanan. Mulai dari membuka rekening sampai pemberian kredit, serta layanan prioritas dan lain sebagainya. Tentu dalam menjalankan kegiatan operasionalnya, bank BRI kantor cabang Manado memanfaatkan teknologi informasi yang tersedia. Dalam hal ini bank BRI kantor cabang Manado menggunakan sistem informasi berupa aplikasi dalam menjalankan kegiatan operasionalnya. Agar supaya terhubung dengan kantor pusat dan juga cabang lainnya, bank BRI kantor cabang Manado menerapkan apikasi tersebut sesuai dengan standar operasional perusahaan (SOP) yang berlaku dalam bank BRI. Dengan menerpakan teknologi informasi dalam hal ini sistem informasi berupa aplikasi, tentunya memberikan banyak manfaat bagi BRI kantor cabang Manado dalam melakukan kegiatan operasionalnya.

\subsection{Pembahasan}

Sistem informasi yang digunakan oleh bank BRI kantor cabang Manado terdiri dari 6 aplikasi yang menunjang proses bisnis perbankan. Keenam aplikasi tersebut terdiri dari:

1. Core Banking System/BRINETS. Aplikasi real time online yang berfungsi menghubungkan kantor pusat dengan kantor cabang serta kantor unit yang ada diseluruh pelosok Indonesia. Salah satu aplikasi CBS yang di terapkan bank BRI kantor cabang Manado, yaitu aplikasi BRINETS. Aplikasi ini merupakan inti dari semua kegiatan operasional bank BRI yang saling menghubungkan cabang lainnya ke kantor pusat secara langsung namun bersifat online. Dengan adanya BRINETS seluruh kegiatan operasional bank terasa sangat simple dan mudah. Mulai dari pelaporan pertanggungjawaban semua cabang bank BRI dapat dengan mudah tersalurkan ke kantor pusat secara cepat dan tepat.

2. Electronic Banking (e-banking). Electronic banking merupakan salah satu aplikasi sistem informasi yang digunakan bank BRI. Electronic banking berfungsi untuk memudahkan nasabah dalam mengakses dan melakukan kegiatan perbankan secara online. Nasabah dapat dengan mudah melakukan transfer uang ke rekening lain dengan menggunakan electronic banking. Bukan cuma itu saja, sekarang dengan adanya electronic banking para calon nasabah dapat dengan mudah membuka rekening melalui sistem electronic banking. Hal itu didukung dengan adanya BRI Hybrid lounge. Para calon nasabah tidak perlu repot mendatangi dan mengantri di kantor operasional BRI, melainkan cukup dengan mendatangi BRI Hybrid lounge para calon nasabah dapat dengan mudah membuka sendiri rekening tabungan.

3. Security System. Security system merupakan aplikasi pertahanan yang dimiliki oleh bank BRI. Penggunaanya bertujuan untuk melindungi data personal nasabah agar tidak bocor ke pihak yang tidak bertanggung jawab. Penggunaan security system tergolong sangat penting dalam kegiatan operasional bank BRI. Apabila data nasabah sampai bocor ke pihak luar, maka kepercayaan nasabah akan berkurang terhadap bank sehingga para nasabah akan menarik seluruh uangnya dan dapat menyebabkan bank jatuh bangkrut.

4. Enterprise Data Model (EDM). Merupakan pengaplikasian model grafis dari data yang digunakan oleh perusahaan. Ciri utama dari kegiatan ini termasuk Model Data Perusahaan yang terdiri dari Entity Relationship Diagrams (ERD), XML Schemas (XSD), dan kamus data perusahaan yang luas. Menggunakan model seperti itu memungkinkan bisnis untuk mendapatkan pandangan 'helikopter' tentang perusahaan mereka. Dalam EAI (Enterprise Application Integration), EDM memungkinkan data direpresentasikan dalam idiom tunggal, memungkinkan penggunaan sintaks umum untuk XML layanan atau operasi dan model data fisik untuk pembuatan skema database. Alat Pemodelan Data untuk ERD 
yang juga memungkinkan pengguna untuk membuat kamus data biasanya digunakan untuk membantu pengembangan EDM.

5. Availability Jaringan Komunikasi. Availability jaringan komunikasi merupakan aplikasi sistem informasi yang menunjukan ketersediaan jaringan informasi. Melalui aplikasi ini bank BRI dapat mengontrol lalu lintas jaringan yang sedang berjalan. Jika kedapatan salah satu sistem yang offline maka pihak bank BRI dapat memperbaikinya melalui aplikasi ini. Aplikasi ini juga memungkinan jaringan komunikasi perusahaan berjalan dengan sistematis dan akurat. Didukung dengan beberapa satelit bank BRI yang mengudara di seputaran orbit bumi membuat ketersediaan jaringan komunikasi dapat berjalan dengan tingkat kompleksitas yang tinggi dengan akurasi yang tinggi juga. Sehingga dapat membuat kegiatan operasional bank BRI menjadi lebih kondusif mengurangi miss komunikasi jaringan.

6. Business Continuity Plan dan Disaster Recovery Plan. Business Continuity plan dan disaster recovery plan merupakan aplikasi yang berfungsi untuk mengurangi risiko operasional bank BRI. Jika terjadi kegagalan sistem, maka diperlukan peran dari aplikasi business continuity plan dan disaster recovery plan.

Tentunya dalam penggunaan teknologi informasi yang baik dan optimal terdapat beberapa manfaat yang berguna dalam menunjang kegiatan proses bisnis perbankan antara lain:

1. Dapat dengan mudah melakukan kontrol perusahaan. Penggunaan teknologi informasi seperti halnya CBS yang telah dilakukan BRI menjadikan setiap sistem yang ada menjadi lebih terkordinir dan terintegrasi secara sistematis. Dalam hal ini justru akan mempermudah pihak bank dalam mengetahui perkembangan bisnisnya dalam sistem karena data- data yang tersedia selalu online dan up to date. Perusahaan juga dapat menghubungkan kantor pusat dengan kantor cabang yang tersebar di seluruh Indonesia dalam hal pengawasan kegiatan operasional agar supaya terhindar dari kegagalan dalam melakukan kegiatan bisnis perbankan.

2. Membantu dalam pengambilan keputusan. Dengan penggunaan teknologi informasi yang baik dan optimal dapat membantu pihak top management dalam hal pengambilan keputusan perusahaan. Hal ini memberikan kemudahan bagi top management melalui ketersediaan informasi yang tersedia secara lengkap dan terkordinir yang dapat berpengaruh dalam hal pengambilan keputusan.

3. Meningkatkan Produktivitas. Dengan adanya teknologi informasi dapat membantu perusahaan dalam meningkatkan proses produksi. Pihak operasional perusahaan dapat dengan mudah melakukan kegiatan produksi dengan diberikan kemudahan terhadap sistem informasi yang tersedia.

\section{KESIMPULAN DAN SARAN}

\subsection{Kesimpulan}

PT. Bank Rakyat Indonesia (Persero) Tbk., merupakan salah satu badan usaha milik negara terbesar di Indonesia. Salah satu cabangnya, yaitu BRI kantor cabang Manado menerapkan teknologi informasi terhadap kegiatan proses bisnis perbankan. Dalam proses pengkordinasian proses bisnis BRI kantor cabang Manado dengan kantor pusat dan kantor cabang lainnya, BRI kantor cabang Manado menggunakan core banking system, electronic banking, enterprise data model (edm), business continuity plan, avaibility jaringan komunikasi, dan security system sebagai aplikasi sistem informasi dalam penerapan teknologi informasi. Dalam penggunaan teknologi informasi, terdapat berbagai macam manfaat. Salah satu manfaat, yaitu membantu dalam pengambilan keputusan.

\subsection{Saran}

Dalam penerapan teknologi informasi terhadap proses bisnis perbankan, pastinya akan banyak menimbulkan kendala berupa gangguan teknologi. Saran dari penulis, sebaiknya 
pihak perusahaan harus segera membuat rencana kedepan dalam meminimalisir resiko penggunaan teknologi informasi di masa yang akan datang.

\section{DAFTAR PUSTAKA}

Arbie, Erwan. 2000. Introduksi Sistem Informasi Manajemen. Jakarta: Bina Alumni Indonesia.

Abdul Kadir dan Terra CH Triwahyuni. 2003. Pemahaman Teknologi Informasi. Yogyakarta: Andi.

Bank Indonesia. 1998. Undang-Undang Nomor 10 Tahun 1998 tentang Pergantian UndangUndang Nomor 7 Tahun 1992 mengenai Perbankan. Jakarta: Gramedia.

Dai Robi Abdullah Fakih, Muthamainnah, Entar Sutisman. 2014. Pengaruh Sistem Informasi Akuntansi dan Pemanfaatan Teknologi Informasi Terhadap Kinerja Manajerial (Bank Papua Cabang Jayapura). Future: Jurnal Manajemen dan Akuntansi, 2(1), 79-87.

Haag dan Keen. 1996. Information Technology: Tomorrow's Advantage Today. Hammond: Mcgraw-Hill College.

Hasibuan, Malayu. 2005. Dasar-dasar Perbankan. Jakarta: Bumi Aksara.

Henni Indrayani. 2012. Penerapan Teknologi Informasi dalam Peningkatan Efektifitas, Efisiensi, dan Produktivitas Perusahaan. Jurnal El-Riyasah, 3(1), 59-64.

Ikatan Akuntansi Indonesia. 2002. Standar Akuntansi Keuangan. PSAK. No.31: Perbankan. Jakarta : Salemba Empat.

Jogiyanto, H.M. 2008. Metodologi Penelitian Sistem Informasi. Yogyakarta: Andi Offset.

O’Brien, James A. 2005. Pengantar Sistem Informasi Akuntansi: Pandangan Bisnis dan Manajerial, Terjemahan edisi 12. Jakarta: Salemba Empat.

PT. Bank Rakyat Indonesia (Persero) Tbk. 2018. Sejarah Bank Bakyat Indonesia. https://bri.co.id/sejarah. Diakses 19 November 2018.

Sutarman. 2012. Introduksi Teknologi Informasi. Jakarta: Bumi Aksara. 